\title{
Control del colapso del colágeno: desproteinización
}

\author{
Osorio Ruiz E*
}

\section{RESUMEN}

La penetración de la resina y su reacción con los componentes de los tejidos dentales desmineralizados es el mecanismo micromecánico con el cual los materiales restauradores de resina se unen al diente. Los monómeros penetran en la dentina acondicionada y se concentran en la región superficial contribuyendo a la unión. El refuerzo de esta zona con resina se conoce como hibridación, e implica la impregnación de la red de colágeno y el encapsulamiento de los cristales de hidroxiapatita. Han surgido dudas en cuanto a la contribución de la red de colágeno en el ensamblaje de la unión y en la fuerza interfacial, ya que el aumento del grosor de la red de colágeno no aumenta dicha fuerza y la remoción del colágeno con hipoclorito sódico al $5 \%$ en solución acuosa da valores similares de fuerza a los que se obtienen cuando la red de colágeno está presente.

Palabras clave: Desproteinización, adhesión, dentina.

\section{ABSTRACT}

Resin penetration into and its reaction with the components of conditioned, mineralised dental tissues is known to be the fundamental micromechanical mechanism by which restorative materials can be successfully bonded to teeth. Monomers penetrated into conditioned dentin and concentrated in a superficial region of resin-reinforced dentin contributing significantly to the bond. The reinforcement, known as hybridization, involved impregnation, co-mingling and envelopment of collagen bundles and encapsulation of hydroxyapatite crystallites. A doubt raised concerning the quantitative contribution which the collagen network made to interfacial bond strength. Increasing the thickness of the collagen network did not influence the assembly strength, and removal of the collagen with $5 \%$ sodium hypochlorite provided similar values to those recorded when the network was present.

Key words: Collagen removal, dentin, adhesion.

Aceptado para publicación: Octubre 2003.

* Profesor Titular de Materiales Odontológicos. Universidad de Granada.

Osorio Ruiz E. Control del colapso del colágeno: desproteinización. Av. Odontoestomatol 2004; 20-3: 123-130.

La dentina puede ser descrita como un composite biológico, con un relleno de cristales de hidroxiapatita y una matriz formada por una red de fibras de colágeno (Marshall GW, Yücel $\mathrm{N}$, Balooch $\mathrm{M}$, et al 2001). Los cristales de hidroxiapatita se incluyen en la matriz dando resistencia al tejido, mientras que la matriz de colágeno lo provee de dureza. La dentina contiene unos túbulos que se extienden desde la unión amelodentinaria hasta la cámara pulpar. Cada túbulo tiene forma de cono invertido y elongado, con un diámetro de unos $0.8 \mathrm{~mm}$ en la unión amelodentinaria y otro mayor de $3.0 \mathrm{~mm}$ en la cámara pulpar. Cada túbulo está delimitado por dentina, llamada, peritubular, más mineralizada que la intertubular dispuesta entre los túbulos (Kinney JH, Balooch M, Haupt DL et al. 1995). Como los túbulos convergen hacia la cámara pulpar, el área de dentina intertubular decrece y la densidad tubular 
aumenta conforme profundizamos hacia la cámara pulpar.

La baja porosidad de la dentina intertubular mineralizada limita la penetración de la resina adhesiva en el túbulo dentinario. En adición, la dentina cortada está casi cubierta por restos de dentina, barrillo dentinario, que se introduce en los túbulos formando los que se denominan tapones de barrillo dentinario, restringiendo la entrada de la resina adhesiva dentro de los túbulos. La fuerza de adhesión de las primeras resinas adhesivas, que se aplicaban directamente sobre la dentina cubierta de barrillo dentinario, fue baja, debido a la baja fuerza cohesiva de las partículas constituyentes del mismo. Así la presencia de barrillo dentinario y de tapones tubulares de barrillo disminuye la permeabilidad en la luz de los túbulos, llamada también permeabilidad intratubular. Por ello es necesaria la remoción de los tapones tubulares, para permitir la formación de tags de resina, y que los monómeros puedan entrar en la luz de los túbulos dentinarios y desplazar su contenido líquido para formar el tag. Tal penetración es necesaria para sellar los túbulos con resina y proteger la pulpa de irritantes.

La permeabilidad de la dentina intertubular, llamada también permeabilidad transdentinal o intertubular, no es uniforme en todo el diente. La permeabilidad de la dentina coronal es mayor que la de la dentina radicular. Incluso en la propia dentina coronal es evidente la no-uniformidad de la permeabilidad, en la dentina profunda existe mayor densidad tubular y por tanto mayor permeabilidad que en la superficial.

Los acondicionadores ácidos se usan, no solo para aumentar la permeabilidad intratubular, mediante la remoción de los tapones de barrillo dentinario, sino también para aumentar la permeabilidad de la dentina intertubular; esta permeabilidad nunca ha sido cuantificada pero debe de ser muy baja o limitada debido a la existencia de canales laterales que parten de los túbulos dentinarios.

Se ha visto que cuando la superficie de dentina es desmineralizada con un acondicionador ácido, no sólo se desmineraliza el barrillo dentinario, sino que también lo hacen de 2 a $5 \mathrm{~mm}$ de profundidad de matriz intertubular. Esta matriz desmineralizada consiste en una red de fibrillas de colágeno que forma microcanales, los cuales hacen posible la infiltración de los monómeros hidrofilicos de resina adhesiva en esta matriz intertubular, lo que es esencial para el aumento de la unión (Gwinnett, 1993), dando lugar a la denominada capa híbrida descrita por Nakabayashi en 1982 (Nakabayashi et al. 1982). Este mecanismo produce un aumento de la fuerza de adhesión comparada con los métodos anteriores. El presente concepto de adhesión a dentina está basado, por tanto, en la retención micromecánica debida a la infiltración de los monómeros hidrofilicos a través de los nanoespacios de la red de colágeno, formando una estructura mixta con fibras de colágeno rodeadas de resina y de cristales de hidroxiapatita residuales.

Para conseguir una unión satisfactoria a dentina, la red de fibras de colágeno, privada del soporte mineral por el grabado ácido, adquirirá la calidad de una esponja, soportada por su contenido líquido, haciendo posible la interdifusión de los monómeros de resina durante la imprimación, esto dio lugar a la aplicación de adhesivos basados en solventes orgánicos que facilitarían la evaporación del agua para ser sustituida por la resina hidrofílica (Kanka 1992, Gwinnett 1992, Perdigao, Swift ECloe 1993); para ello la dentina no debe estar demasiado seca evitando así el colapso de las fibras de colágeno (Eick \& Others, 1997), ni demasiado húmeda pues limitaría la penetración de la resina, dando lugar en ambos casos y también como resultado de una incompleta infiltración de monómeros dentro de la matriz intertubular desmineralizada a zonas de red de colágeno sin infiltrar por resina susceptibles de hidrólisis y por tanto serían zonas por donde se podría producir el fracaso de la restauración. Los adhesivos basados en agua pueden usarse cuando la dentina se ha desecado , en este caso el componente acuoso del adhesivo reexpande la red de colágeno (Nakabayashi $\mathcal{E}$ Pashley 1998), pero la red de colágeno no se reexpande como originalmente está con lo que también se producen zonas donde el primer no llega.

En este punto radica la dificultad de conseguir una buena unión a dentina, en conseguir la humedad crítica de la dentina, es decir, la humedad óptima para que los monómeros de resina puedan penetrar en la red de colágeno sin ser entorpecidos por su contenido líquido o por el colapso de dicha red. A todo esto 
se le añade la dificultad de la proximidad de este tejido al esmalte dentario que para su optima unión a la resina debe de estar completamente seco.

En base a este requerimiento de la dentina, se han desarrollado dos técnicas distintas de adhesión: la primera en la que se debe conseguir dicha humedad crítica en la dentina acondicionada, consiguiendo una superficie dentinaria húmeda y brillante pero sin cúmulos de agua, al lado de un esmalte que debe estar seco; (objetivo imposible de conseguir) a esta técnica se le ha denominado técnica húmeda de adhesión. Y la segunda técnica en la que la dentina se seca para ser luego rehidratada con un primer que contiene agua, se ha demostrado que el colapso de las fibras de colágeno es reversible, hasta cierto punto, aplicando primers con contenido en agua. A esta se le ha llamado la técnica seca de adhesión. El problema de esta técnica está en que durante la imprimación se humedece el esmalte, con lo que disminuye la fuerza de adhesión a este tejido y además la reexpansión de las fibras de colágeno nunca llega a ser como la expansión original.

Para evitar esto tenemos dos opciones: en primer lugar seguir escrupulosamente el procedimiento aconsejado por el fabricante, para asegurarnos, en la medida de lo posible, de que el primer llega a impregnar toda la dentina que el ácido ha acondicionado; lo cual la mayoría de la veces no es posible. Tay y colaboradores demostraron que la incorrecta aplicación de estos sistemas puede crear, lo que denominaron, una capa hibridoide con numerosos huecos y porosidades sin resina infiltrada en la dentina desmineralizada, también nociva para la restauración (Tay FR Gwinnett AJ, Pang KM. 1995). Otros estudios demuestran que la presencia de humedad, en la zona rica en colágeno de la dentina grabada, es crítica para que algunos primers consigan la fuerza de adhesión optima.

En segundo lugar, utilizar sistemas adhesivos autograbadores, donde el acondicionamiento y la imprimación se hacen a la vez y en un solo frente y en tercer lugar, eliminar la capa de red de colágeno (Marshall GW, Yücel N, Balooch M, et al 2001) con un agente desproteinizante que podría facilitar el acceso de la resina adhesiva al sustrato que será más permeable (Inaba \& Others 1995).
Otro aspecto a tener en cuenta es la humectabilidad, este es uno de los factores más importantes en la adhesión. Debe haber un íntimo contacto entre el adhesivo y la dentina acondicionada para permitir la infiltración de la resina adhesiva. Por lo tanto la tensión superficial del adhesivo debe de ser lo más baja posible, y la energía superficial del substrato lo más alta posible (se ha demostrado una correlación directa entre la energía superficial de la dentina y la fuerza de adhesión). Los cambios producidos en el contenido mineral del substrato, durante el grabado ácido, pueden cambiar la energía superficial de la dentina. La hidroxiapatita es un substrato de alta energía superficial que favorece la humectabilidad y el colágeno es de baja energía superficial y desfavorece la humectabilidad, con lo que al acondicionar la dentina estamos disminuyendo la energía superficial de esta superficie y por consiguiente desfavoreciendo la humectabilidad de la misma. De hecho, hay una correlación entre la capacidad del adhesivo para difundirse en la superficie de dentina y la concentración de calcio en la misma superficie.

Por tanto físicamente estamos favoreciendo la humectabilidad y químicamente la estamos dificultando, lo ideal sería una superficie con estás características físicas pero químicamente como la dentina sin grabar y sin barrillo dentinario, con mayor energía superficial. Por lo tanto existen dudas sobre el papel de las fibras de colágeno en la adhesión y en la eficiencia del sellado de los adhesivos a la dentina desmineralizada. Se ha observado, también, microfiltración alrededor de muchas restauraciones unidas con varios adhesivos dentinarios. Se ha visto, nanofiltración, una filtración microscópica, dentro del espesor de la capa híbrida, lo que sugiere que puede incluso existir porosidad dentro de la estructura de dicha capa.

Nosotros realizamos un trabajo cuyo objetivo fue caracterizar la superficie de la dentina pulida, grabada con ácido y desproteinizada con hipoclorito sódico al 5\% durante 2 minutos (Toledano M, Osorio R, Perdigao J, Rosales JI et al 1999). El hipoclorito sódico es un agente proteolítico no específico (Marshall GW, Yücel N, Balooch M, et al 2001) que, efectivamente, remueve los componentes orgánicos de la dentina; el colágeno desestabilizado superficial y el barrillo dentinario remanente del grabado ácido, 
cambiando, además, su composición química (Inaba D, Duschner H, Jogenbloed W. et al. 1995, Sakae, Mishima \& Kizawa, 1988). Este substrato desproteinizado es rico en cristales de hidroxiapatita expuestos (Wakabayashi $\varepsilon$ others 1994) y puede dar lugar a una interfase estable en el tiempo, pues está, esencialmente, compuesta de mineral lo mismo que el esmalte grabado (Tanaka \& Nakai, 1993). Autores como Perdigao (1999) describio, que después del tratamiento con hipoclorito sódico durante sólo dos minutos, la superficie de dentina tiene unos túbulos dentinarios más abiertos, debido a la perdida de dentina peritubular desmineralizada, lo cual también disminuye el área de dentina intertubular residual. El diámetro de las ramas laterales de los túbulos también aumenta y son más numerosas, que con el grabado ácido sólo, lo que produciría tags de resina más fuertes, Perdigao y colaboradores (1999) encontraron un extenso entramado de canales secundarios con numerosas anastomosis abiertas hacia la región intertubular y hacia la luz de los túbulos. Existiendo, también, finas irregularidades en la dentina intertubular desproteinizada que aumentarían la retención de la resina, lo cual produciría una clara diferencia en comparación con la superficie obtenida con el uso del ácido ortofosfórico sólo.

Autores como Pratti C (1992), Wakabayashi Y (1994) y Gwinnett (1996) han demostrado que aumenta la adhesión en dentina desproteinizada y mejora su permeabilidad (Inaba $\mathcal{E}$ others, 1995). En las fotografías de microscopía electrónica de barrido pueden apreciar la diferencia entre dentina grabada y dentina desproteinizada. Los resultados mostraron que el tratamiento de la dentina tiene un efecto significativo en la rugosidad de la misma (Toledano $M$, Osorio R, Perdigao J et al 1999).

El grabado ácido aumenta la rugosidad de la dentina profunda, cuando la dentina superficial se desproteiniza no varía su rugosidad respecto de la dentina grabada esto es debido a la mayor densidad tubular y la apertura de los lúmenes tubulares. Cuando la rugosidad aumenta el ángulo de contacto que produce el agua disminuye, así, el ángulo de contacto disminuye cuando la dentina grabada es comparada con la dentina pulida (pues es más rugosa), independientemente de la profundidad de la misma. El ángulo de contacto obtenido en la denti-

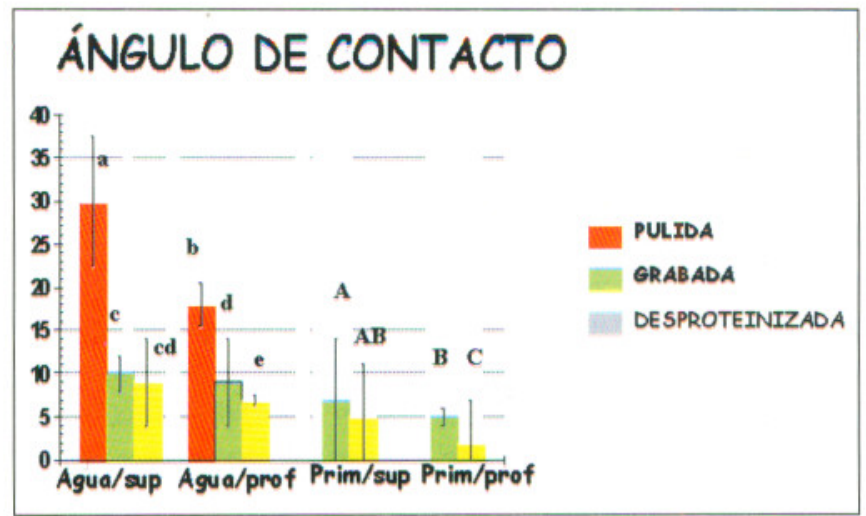

Gráfica 1

na superficial grabada es similar a la dentina superficial desproteinizada, pero diferente a la dentina profunda (Gráfica 1).

En cuanto al ángulo de contacto del primer: en dentina superficial no existen diferencias significativas entre grabada y desproteinizada. En dentina profunda el ángulo de contacto era mayor en la grabada que en la desproteinizada.

Entre ambos tipos de dentina existieron diferencias estadísticamente significativas tanto en pulida, grabada como desproteinizada. En dentina profunda el ángulo de contacto era menor tanto con el primer como con el agua.

Hay que tener en cuenta que existen diferencias mor-

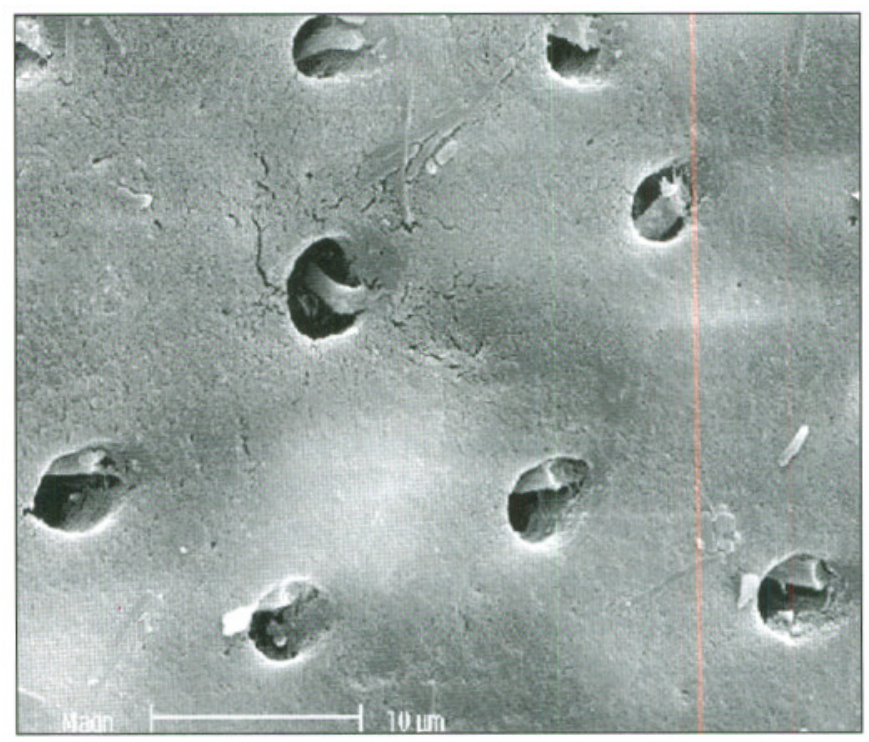

Fig. 1. Dentina desmineralizada. 


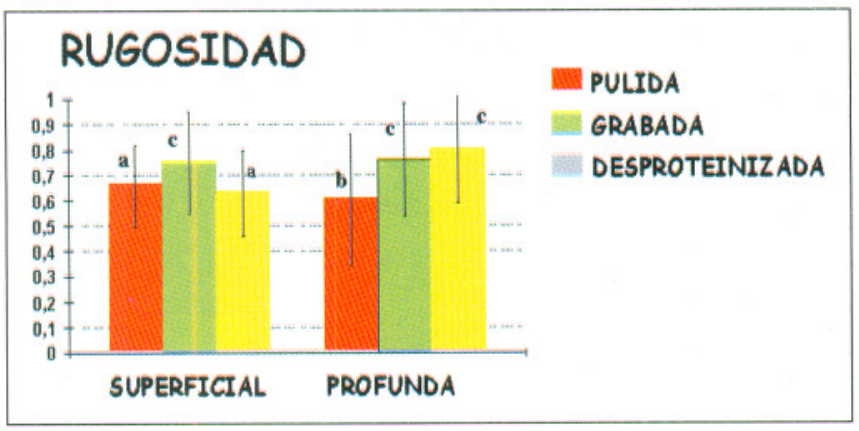

Gráfica 2

fológicas entre la estructura de la dentina profunda y la dentina superficial, que podrían dar cuenta del comportamiento clínico y mecánico de ambos tejidos; el número relativo de túbulos expuestos, el área de dentina peritubular, y el área ocupada por dentina intertubular varía dramáticamente dependiendo de la profundidad de la dentina que está siendo observada (Perdigao J, Thompson JY, Toledano M, Osorio R 1999). La remoción del colágeno en dentina superficial no parece jugar un papel importante en la fuerza de adhesión obtenida en este substrato. Estudios previos han demostrado que la humectabilidad no aumenta en dentina superficial cuando se deproteiniza Otros autores no obtienen diferencias entre las fuerzas de adhesión en dentina superficial grabada y dentina superficial grabada/deproteinizada.

Sin embargo en la dentina profunda grabada cuando se desproteiniza aumenta la humectabilidad debido a cambios químicos (aumento de la concentración de iones calcio, hidroxiapatita) en la superficie y a cambios en su acción capilar, ya que aumentan los lúmenes de los túbulos además de remover el colágeno expuesto de baja energía superficial. Cuando la dentina profunda es grabada y deproteinizada, la fuerza de adhesión aumenta un 37.5\% llegando a valores similares a los obtenidos en dentina superficial grabada.

Nosotros realizamos un estudio que tenía como objetivo comparar las fuerzas de adhesión que se producen entre el Prime $\mathcal{E}$ Bond 2.1 y la dentina superficial grabada y grabada y desproteinizada y la dentina profunda grabada y grabada y desproteinizada. Los resultados de este estudio mostraron que la profundidad de la dentina y el tratamiento de la misma no influian si se evaluaban de forma indepen-

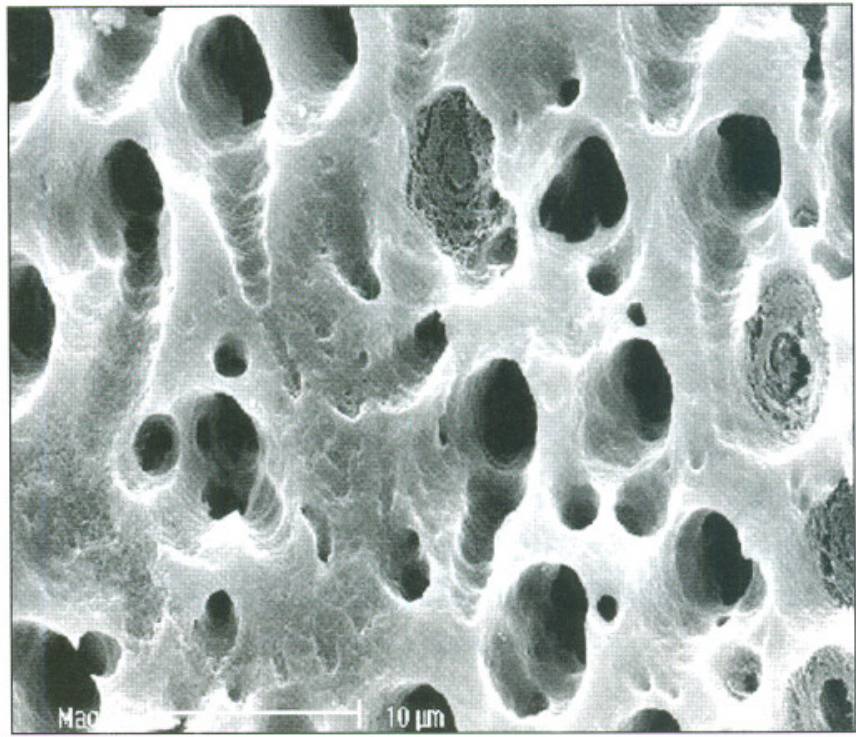

Fig. 2. Dentina desmineralizada y desproteinizada.

diente pero existían interacciones positivas.(gráfica 2) (Toledano M, Perdigao J, Osorio E, et al 2000).

Después del grabado la fuerza de adhesión era mayor en la dentina superficial que en la profunda. Cuando se aplicaba hipoclorito la fuerza de adhesión aumentaba significativamente en la dentina profunda, pero bajaba levemente (no significativo estadísticamente) en la superficial.

Después de la aplicación de hipoclorito, superficial y profunda mostraron una fuerza de adhesión estadísticamente igual. El fallo en la tracción fue adhesivo en la mayoría de los casos.

Por lo tanto y en resumen la remoción del colágeno con hipoclorito sódico da lugar a una superficie irregular, rica en hidroxiapatita, que permite el sellado completo de los túbulos con resina y no forma capa híbrida.

En las figuras 2 y 3 tienen imágenes de microscopía electrónica de barrido donde se puede apreciar la diferencia entre la adhesión que se produce en dentina grabada y la que se produce en dentina grabada y desproteinizada.

Realizamos otro estudio para evaluar el sellado de las restauraciones cuando se desproteinizaba la dentina mediante microfiltración con Fuccina. El objetivo del 


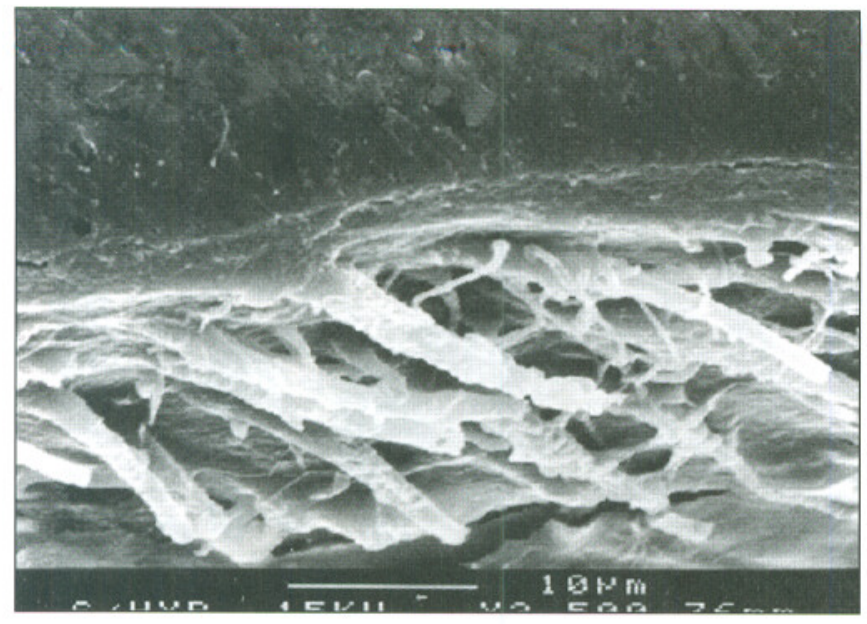

Fig. 3. Adhesión con colágeno.

estudio fue evaluar la microfiltración de restauraciones de clase $V$ de resina cuando se graba la dentina con $\mathrm{H}_{3} \mathrm{PO}_{4}$ al $36 \%$ y posteriormente se desproteiniza con $\mathrm{NaOCl}$ al $5 \%$ en solución acuosa.

Los resultados del estudio mostraron que no existían diferencias entre la dentina grabada o el esmalte grabado y la dentina desproteinizada o el esmalte desproteinizado en ninguno de los márgenes de la restauración, pero si existían diferencias entre los márgenes siendo el oclusal el que más filtración presentaba (Gráfica 3).

Otros estudios han demostrado mayor efecto positivo del hipoclorito sódico en la fuerza de adhesión con los adhesivos basados en acetona (Saboia V de Pa, Rodríguez AL, Pimenta LAF. 2000) que los adhesivos basados en etanol/agua, esto puede ser debido a la mayor capacidad de la acetona para desplazar el agua del substrato, este factor puede aumentar el contacto de los monómeros con la estructura irregular de dentina expuesta tras el tratamiento con hipoclorito. Además los adhesivos basados en agua/etanol difunden más lentamente que los adhesivos basados en acetona, por lo que el intervalo de tiempo que los fabricantes recomiendan para los primeros parece ser insuficiente como para permitir una completa difusión de los monómeros dentro del substrato.

De todas formas la remoción del colágeno aumenta el contacto entre el adhesivo y los cristales de hidroxiapatita por una aumento de la permeabilidad dentinaria.

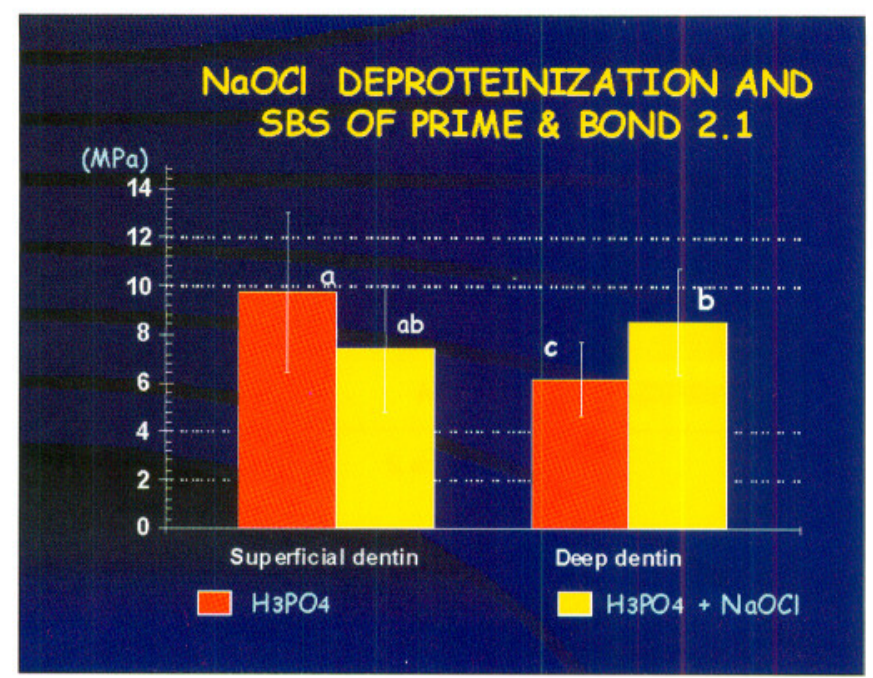

Gráfica 3.

La aplicación de hipoclorito, además, puede tener otros beneficios adicionales como su efecto antimicrobiano y el ser un agente solvente que puede desinfectar y limpiar el tejido dental de restos orgánicos.

Pero recientemente se ha puesto de manifiesto que el efecto del hipoclorito depende del tiempo que se le deje actuar (Prati C, Chersoni S, Pashley DH. 1999), este estudio sugirió que el proceso de desproteinización de la dentina es mucho más lento que el de grabado ácido o desmineralización, la dentina deproteinizada durante varios días aún mostraba presencia de colágeno; esto es debido a que las fibras de colágeno que están encapsuladas por hidroxiapatita no son accesibles al hipoclorito, mientras que el colágeno expuesto en la superficie de la dentina por el proceso de desmineralización es rápidamente atacado y removido.

Por otro lado también se ha demostrado que durante la desproteinización no todas las fibrillas de colágeno se pierden, ya que son más visibles después del tratamiento con hipoclorito en el microscopio de fuerzas atómicas, se ha demostrado que la desproteinización de la dentina es solo parcial y que son otras las proteínas y no todo el colágeno las que se pierden durante esta desproteinización. A esta remoción incompleta del colágeno se le ha atribuido la disminución de la fuerza de adhesión con algunos adhesivos al aplicar hipoclorito.

Otro factor que se ha postulado como responsable 


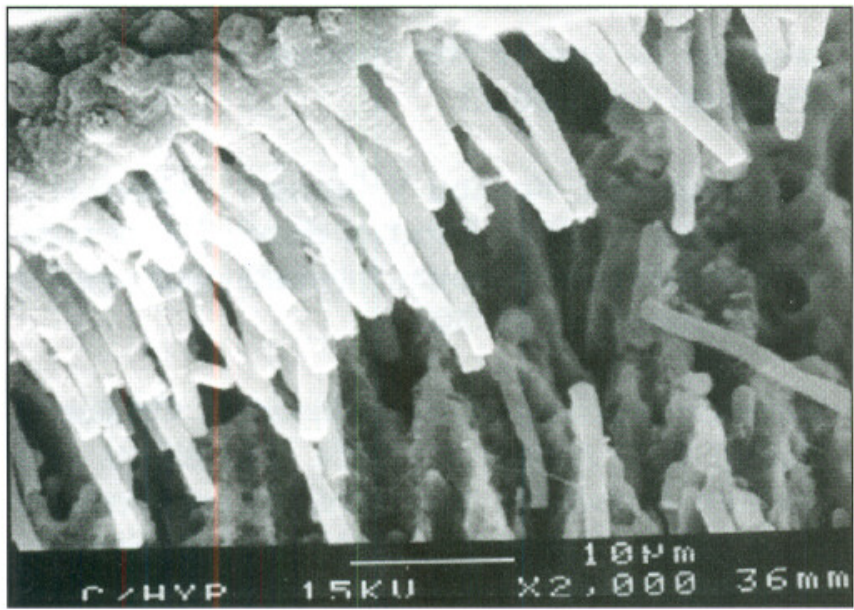

Fig. 4. Adhesión sin colágeno.

de la disminución de la fuerza de adhesión en algunos adhesivos es el efecto oxidante del hipoclorito sódico en dentina, sobretodo con adhesivos basados en acetona, debido a la presencia de radicales libres en la dentina tratada con hipoclorito, que pueden competir con la propagación de los radicales vinilos generados durante la activación por luz del adhesivo, resultando una terminación prematura de la polimerización y por tanto incompleta.

En el caso de la aplicación de agua oxigenada, otro oxidante muy utilizado en odontología, la fuerza de adhesión puede verse afectada por la presencia de solución de agua oxigenada residual en este tejido, que libere oxigeno y agua. La liberación de oxigeno puede también interferir con la infiltración de la resina o inhibir la polimerización de aquellas que polimerizan mediante el mecanismo de radicales libres.

Se está investigando que la disminución de la fuerza de adhesión en la dentina grabada y tratada con hipoclorito es reversible con el tratamiento de la misma con ascorbato de sodio, un antioxidante. A la luz de estos encuentros, es posible que las alteraciones en la adhesión no sean permanentes, y puedan producirse cambios reversibles en el potencial redox de los componentes orgánicos de este tejido. También se especula que los iones hipoclorito pueden sustituir temporalmente a los iones hidroxilo de las moléculas de hidroxiapatita, lo cual es termodinámicamente desfavorable, tal proceso puede ser reversible con un antioxidante como el ascorbato de sodio o el ácido ascórbico.

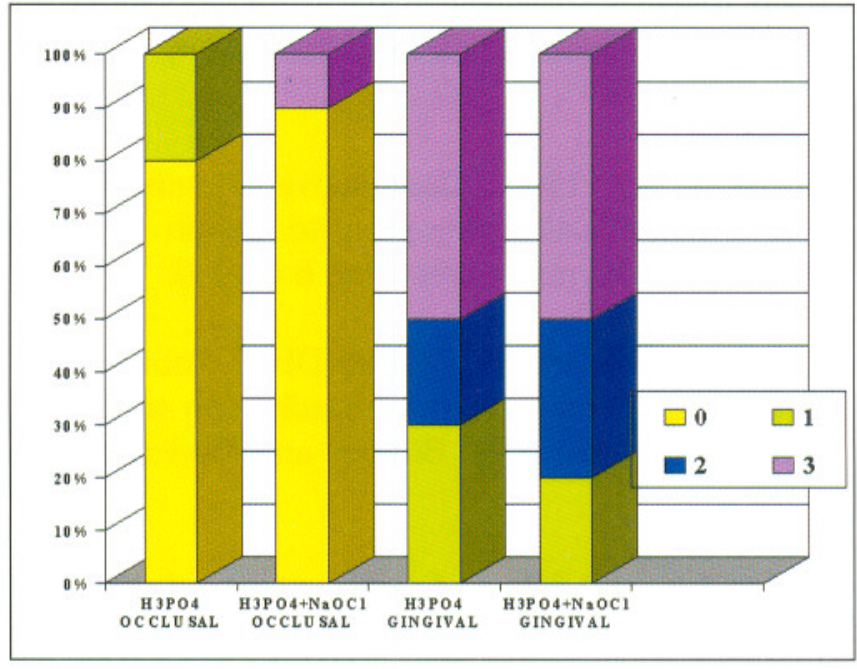

Gráfica 4.

Se está investigando la posible aplicación de ácido ascórbico o de su sal, ascorbato de sodio, como antioxidante capaz de anular los radicales libres en sistemas biológicos, neutralizando el efecto oxidante del hipoclorito sódico.

\section{BIBLIOGRAFÍA}

- Nakabayashi N, Kojima D, Masuhara E.1982. The promotion of adhesion by the infiltration of monomers into tooth substrate. J Biomed Mater Res; 16: 265-73.

- Inaba D, Duschner H, Jogenbloed W, Odelius H, Takagi O, Arends J. 1995. The effects of a sodium hypoclorite treatment on demineralized root dentin. Eur J Oral Sci; 103: 368-74.

- Marchall GW, Yücel N, Balooch M, Kinney JH, Habelitz S, Marshall SJ. 2001. Sodium hypochlorite alterations of dentin and dentin collagen. Surface Science; 491: 444-55.

- Kinney JH, Balooch M, Haupt DL, Marshall SJ, Marshall GW. 1995. Mineral distribution and dimensional changes in human dentin during demineralisation.J Dent Res. 74 (5): 1179-84.

- Perdigao J, Thompson JY, Toledano M, Osorio R.1999. An ultra-morphological characterization 
of collagen-depleted etched dentin. Am. J. Dent. 12: $250-5$.

- Gwinnett AJ. 1993. Quantitative contribution of resin infiltration/hybridisation to dentin bonding American Journal of Dentistry. 6 (1) 7-9.

- Eick JD, Gwinnett AJ, Pashley DH \& Robinson SJ (1997). Current concepts on adhesion to dentin. Critical Review of Oral Biology and Medicine 8 (3) 306-35.

- Kanca J (1992) Effect of resin primer solvents and surface wetness on resin composite bond strength to dentin. American Journal of Denstistry 5 (4) 213-5.

- Gwinnett AJ (1992) Moist versus dry dentin: its effects on shear bond strength. American Journal of Denstistry 5 (3) 127-9.

- Perdigao J, Swift \& Cloe B (1993). Effect of etchants, surface moisture and resin composite on dentin bond strength American Journal of Dentistry 6 (2) 61-4.

- Nakabayashi NE Pashley D (1998) Hibridizatiuon of Dental Hard Tissue New York Quintessence Publishing pp 48-9.

- Inaba D, Duschner H, Jongebloed W, Odelius H, Takagi O \& Arends J (1995) The effects of a sodium hypochlorite treatment on demineralizaed root dentin. European Journal of Oral Sciences 1093 (6) 368-74.

- Tay FR, Gwinnett AJ, Pang DM \& Wei SHY (1995) Variability in microleakage observed in a total etch wet-bonding technique under different handling conditions. Journal of Dental Research 74 (5): 1168-78.

- Gwinnet AJ, Tay FR, Pang KM \& Wei SHI (1996). Quantitative contribution of the collagen network in dentin hybridisation. American Journal of Dentistry 9 (4) 140-4.

- Prati C, Erickson RL, Simpson MD \& Pashley DH (1992) Measurement of dentin permeability and wetness by use of the Peritron device. Dental Materials 7 (4) 268-73.

- Wakabayashi Y, Kondou Y, Suzuki K, Yatani H E Yamashita A (1994) Effect of dissolution of collagen on adhesion to dentin. International Journal of Prosthodontics 7 (4) 302-6.

- Inaba D, Duschner H, Jogenbloed W, Odelius H, Takagi O E Arends J (1995). The effects of a sodium hypoclorite treatment on demineralised root dentin. European Journal of Oral Sciences 103 (6), 368-74.

- Sakae T, Mishima H E Kizawa Y (1988). Changes in bovine dentin mineral with sodium hypochlorite treatment Journal of Dental Research 67 (9) 1229-34.

- Tanaka J E Nakai H (1993) Application or foot canal cleaning agents having dissolving abilities of collagen to the surface treatment for enhanced bonding of resin to dentin. Gental Materials Journal 12 (2) 196-208.

- Wakabayashi Y, Kondou y, Suzuki K, Yatani H E Yamashita A ( 1994) Effect of dissolution of collagen on adhesión to dentin International Journal of Prosthodontics 7 (4) 302-6.

- Toledano M, Osorio R, Perdigao J, Rosales JI, Thompson YJ \& Cabrerizo-Vilchez MA (1999) Effect of acid-etching and collagen removal on dentin wettability and roughness Journal of Biomedical Material Research 47 (2) 198-203.

- Saboia V de PA, Rodrigues AL, Pimenta LAF. 2000. Effect of collagen removal on shear bond strength of two single-bottle adhesive systems. Operative Dentistry 25, 395-400.

- Prati C, Chersoni S, Pashley DH. 2000. Effect of removal of surface collagen fibrils on resin-dentin bonding. Dental Materials 15, 323-31.

- Toledano M, Perdigao J, Osorio E, Osorio R. 2000. Influence of $\mathrm{NaOCl}$ deproteinization on shear bond strength in function of dentin depth. Am J Dent. 15 (4): 252-5. 